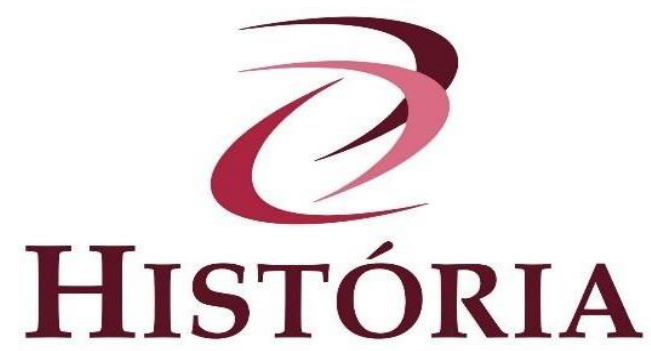

\title{
Construcción sígnica de masculinidad y lazos de homosociabilidad en las historietas
}

\author{
Signic construction of masculinity and ties of homosociability in comics
Construção sígnica da masculinidade e laços de homossociabilidade nos quadrinhos

Mariela Alejandra Acevedo*

\begin{abstract}
Resumen: Este artículo explora la puesta en página de historietas en las que los personajes masculinos entablan - como nudo central en los relatos- lazos de homosociabilidad. Exploramos este concepto desarrollado por Eve Kosofsky Sedgwick (1985) que resulta productivo para analizar cómo se construyen modelos de género a partir de los vínculos entre personajes masculinos en las narrativas y en nuestro caso en una selección de historietas.
\end{abstract}

Palabras clave: Historietas. Homosociabilidad. Revista Fierro.

Abstract: This article explores the putting into page of comics in which the male characters establish - as a central knot in the stories - bonds of homosociability. We explore this concept developed by Eve Kosofsky Sedgwick (1985), which is productive to analyze how gender models are constructed from the links between male characters in narratives and in our case in a selection of comics.

Keywords: Comics. Homosociability. Revista Fierro.

Resumo: Este artigo explora a colocação na página de histórias em quadrinhos em que os personagens masculinos estabelecem - como nó central nas histórias - laços de homossociabilidade. Exploramos esse conceito desenvolvido por Eve Kosofsky Sedgwick (1985), que é produtivo para analisar como os modelos de gênero são construídos a partir das ligações entre personagens masculinos em narrativas e, em nosso caso, em uma seleção de quadrinhos.

Palavras-chave: Quadrinhos. Homossociabilidade. Revista Fierro.

\section{Introducción}

El estudio de relatos centrados en personajes masculinos ha sido explorado ampliamente en el cine y la literatura y de allí recuperamos algunas herramientas para 
aproximarnos a su análisisi. Adrián Melo (2012) revisa en un artículo para el Suplemento SOY (Página 12) la producción cinematográfica y literaria argentina y señala lo que aparece como una forma de amistad apasionada entre varones. Define este rasgo en la cultura como

Ese prototipo incondicional nacido frecuentemente en los bares porteños, alimentado muchas veces en las canchas de fútbol, en confesiones arrancadas por el alba y en otros contextos de hombres sin mujeres en donde florece lo que Eve Kosofsky Sedgwick llamaría homosociabilidad, [algo que] llegó a formar parte de la mitología y el arte argentinos, llenó tan pronto páginas de letras de tango, de obras de teatro y de televisión costumbristas como obras de literatura, desde Kordon hasta Fontanarrosa, pasando por Borges y Cortázar, y recorre las comedias y los dramas populares de la cinematografía argentina, en un arco que puede ir desde Enrique Susini pasando por Leonardo Favio, Enrique Carreras hasta Juan José Campanella. ("De la amistad como forma de vida", en línea)

Atilio Rubino (2017) ha retomado la idea desarrollada por Eve Kosofsky Sedgwick sobre los vínculos entre hombres estructurados a partir de la prohibición de la homosexualidad para pensar vínculos entre varones en el cine de habla alemana. La propuesta de analizar los vínculos intermasculinos en la pantalla apela al concepto de continuum de homosociabilidad en donde se establecen distintas relaciones entre varones que niegan el deseo homosexual. Desde esta perspectiva, heterosexualidad y homosexualidad no constituyen dos expresiones de la sexualidad contrarias en una nueva formulación binaria y excluyente, sino que las relaciones entre hombres - los lazos de homosociabilidad- se hacen "inteligibles mediante su desviación hacia relaciones triangulares que implican a una mujer” (Kosofsky Sedgwick, 1998: 27 citada en Rubino, A. 2017: 54).

Una aproximación a nuestro objeto de indagación se encuentra en la propuesta de David William Foster (2016:13), quien señala que "La historia de los cómics argentinos se centra en los personajes masculinos, y esto se traslada a la ficción gráfica". Entiende que Mafalda, la tira cómica de Quino, es excepcional y señala que el campo estuvo hegemonizado por la mirada masculina hasta la incursión de Maitena, que fecha por 1993 con sus publicaciones ligadas al humor gráfico.

Podríamos matizar estas apreciaciones, en primer lugar, porque — siguiendo a Claudia Ferman (1994) quien aborda la inserción de Patricia Breccia en revista Fierropodemos encontrar espacios en las publicaciones en los que existen fisuras o expresiones de resistencia en donde autoras y lectoras hicieron sentir su presencia. En segundo lugar, porque también es posible sostener que, aunque las historietas no apelen a personajes femeninos, existe un subtexto de género que construye la masculinidad en relación a la feminidad y a otras expresiones de masculinidades no hegemónicas.

La revista Fierro emerge en 1984 al calor de la transición democrática y llega a cien números en 1992 momento en el que clausura su primera etapa. El regreso con el diario 
Página 12 se fecha en octubre de 2006, FIERRO. La historieta argentina cierra esta segunda etapa en enero de 2017 con su número 125. Una tercera etapa, trimestral de 8 volúmenes es editada por Página 12 entre marzo de 2017 y diciembre de 2018. La actual cuarta etapa, Revista Fierro Digital inicia en septiembre 2020 como parte de los contenidos del portal El Destape.

En este texto, abordamos como superficies textuales tres historietas breves publicadas en las dos primeras etapas que nos permiten abordar algunas cuestiones en torno a las masculinidades y el continuum entre heterosexualidad y homosexualidad, entanto no se tratan de identidades discretas sino discursividades en construcción que mixturan orgullo, miedo, homofobia y heterosexismo: relaciones de competencia, amor y amistad entre hombres que nos invitan a pensar en la construcción visual de las masculinidades.

En la siguiente aproximación partimos de historietas donde los personajes femeninos — cuando están - operan como elementos para dinamizar la aventura que sucede entre figuraciones masculinas. Nos interesa partir de algunas escenas para aproximarnos a la relación entre distintas expresiones de masculinidad y cómo se intersecta con las sexualidades y lo normativo como expectativa o como transgresión.

Armamos una serie en la que hacemos jugar en historietas y autores disímiles, de distintas épocas de la publicación: "Señuelo" de Peiró es una historieta autoconclusiva publicada en la primera época de Fierro mientras que las otras dos historietas también autoconclusivas fueron publicadas en la segunda etapa de la publicación: "Mi experiencia con Agé” de Juan Saénz Valiente y, "Canciones cursis para varones" de Ignacio Minaverry. Los tres textos son superficies que visibilizan búsquedas en torno a la representación de otras masculinidades.

Entramos en un mundo de personajes masculinos habitado por otros varones con los que hablan, confrontan y forjan amistades, héroes solitarios que recuerdan a una mujer y se confiesan como solo lo puedan hacer entre hombres. Ponen en escena —en página para ser más precisa - formas aceptables - y representables - de amor entre varones.

\section{Gangsters a la cordobesa: los unitarios de Peiró}

Nos detenemos aquí en uno de los episodios autoconclusivos que publica el dibujante y guionista cordobés Manuel José Peirotti con el seudónimo de Peiró. Sus trabajos se publican en Fierro desde el primer número y hasta la edición 70 en mayo de 1990. Peiró es un dibujante cuya trayectoria se inicia en la década de 1970 en la revista humorística 
Hortensia. En Fierro - y en otras revistas de Ediciones de La Urraca como SuperHum®— explorará otro registro y dará a conocer su perfil como narrador de breves historietas autoconclusivas: Fierro publicó un total de trece historias sobre mundos masculinos del hampa ambientados en pueblos del interior de Córdoba, bandas criminales conformadas por la mano de obra desocupada del Estado, pequeñas historias en las que se traza la historia de colonialismo, racismo y sexismo en los cuerpos de sus personajes. ${ }^{\text {ii }}$ Dice Juan Sasturain (2014: 4-5) en la introducción de la compilación Tinta Mortal:

En las historietas de Peiró, señoras y señores, van a encontrar mucho de lo que ya no hay, de lo que ya no se hace o no se sabe hacer: dibujar fierros, tetas y sombreros bien puestos. De los fierros — vale por máquinas, autos, armas - está casi todo dicho. Son protagonistas centrales, nunca meros instrumentos. De las tetas, como los culos y las virilidades que proliferan, solo cabe decir que pesan, obedecen a la ley de gravedad, son pedazos de carne verdadera. No es frecuente en la figuración erótica femenina - pienso en las memorables minas que dibujaba Solano en Evaristo, por ejemplo- que las mujeres dibujadas existan fuera del papel. Las de Peiró, son carnalmente, lo que hay. (...) Peiró dibuja gente, gente de carne y hueso, por lo general, necesaria, natural y estadísticamente fea: con rasgos de clase, de raza, de estado, de alevosa condición moral.

Estos relatos breves de Peiró suelen basarse en una anécdota que devela un giro de los acontecimientos al final que sorprende a la lectora. Este es el mecanismo que pone en marcha el autor en "Señuelo", el relato gráfico en el que indagaremos para abordar los modelos de masculinidad que delinea la trama. La historieta de seis páginas, en blanco y negro, fue publicada en Fierro n`39 en noviembre de 1987 y nos interesa porque plasma de forma explícita la masculinidad como una construcción que puede ser desmontada.

El relato comienza con un personaje que no vemos pero que relata en off mientras se despliega visualmente al narrador-protagonista en el pasado y accedemos a los hechos desde su relato en el presente. La primera viñeta nos sitúa como espectadoras/es de una historia en la que el protagonista se encuentra en un paraje natural, solo, intentado pescar. La pesca, una actividad habitualmente considerada masculina y el título "Señuelo" comparten una serie de connotaciones que irán hilándose en el relato de Peiró. El juego entre las apariencias se presenta desde la primera página cuando el pescador refiere al pez que acaba de picar el anzuelo “¡Se lo tragó entero!”. El texto subraya verbal y gráficamente la idea de un primer escenario salvaje y solitario donde irrumpe una mujer, semidesnuda, que lo observa y a la que el protagonista no se explica por qué "debe seguir". Él interrumpe su actividad y se lanza tras la mujer, a la que desde el inicio animaliza: "trepaba como una cabra" dirá en su relato. La joven lo conduce a una choza y allí, sin mediar palabra, en ese estado donde la comunicación apela a formas "naturales", Peiró grafica las escenas sexuales del encuentro y en la anécdota que narra se solapan el espacio en el que se encuentran — una especie de refugio- con el 
cuerpo de la mujer: "Nunca olvidaré esas horas que pasé ahí dentro...”. Y luego, el relato, señala algunas pistas que entenderemos recién al final: "Quizás cueste creerlo, viéndome ahora. Pero esa fue una experiencia única en mi vida... Ninguna droga podría duplicarla".

Esa experiencia de encuentro sexual inigualable que describe el narrador de forma hiperbólica también se puede enmarcar en una experiencia social masculina de "cuentos" entre hombres. El narrador avanza en su relato y presenta el conflicto: en algún momento fue sorprendido por un personaje que rompe el idilio. El peligro emerge cuando este personaje obliga al protagonista a salir de la cabaña y comienza a amedrentarlo empuñando un arma: Lo amenaza y se burla, pone el arma en su boca y le dice "¡Abra la boca como un hombrecito!” o “iQué pena tener que matar a un macho como vos!”. La intervención de la mujer descrita como salvaje deja inconsciente a quien (sabremos entonces) era su pareja, y se abre paso a la explicación.

Con el personaje del amante celoso aun inconsciente por el golpe, la salvaje le explica al pescador desconocido que de vez en cuando necesita un hombre. El pescador entonces pregunta por el desmayado y la joven procede a desnudar y a exponer el cuerpo de su amante, que permanece inconsciente: la viñeta muestra entonces la genitalidad como la verdad del sexo de esa masculinidad: es un cuerpo asignado "mujer" pero que presenta los códigos sociales que identificaríamos como los de un varón y la trama presenta la escena como "engaño". 


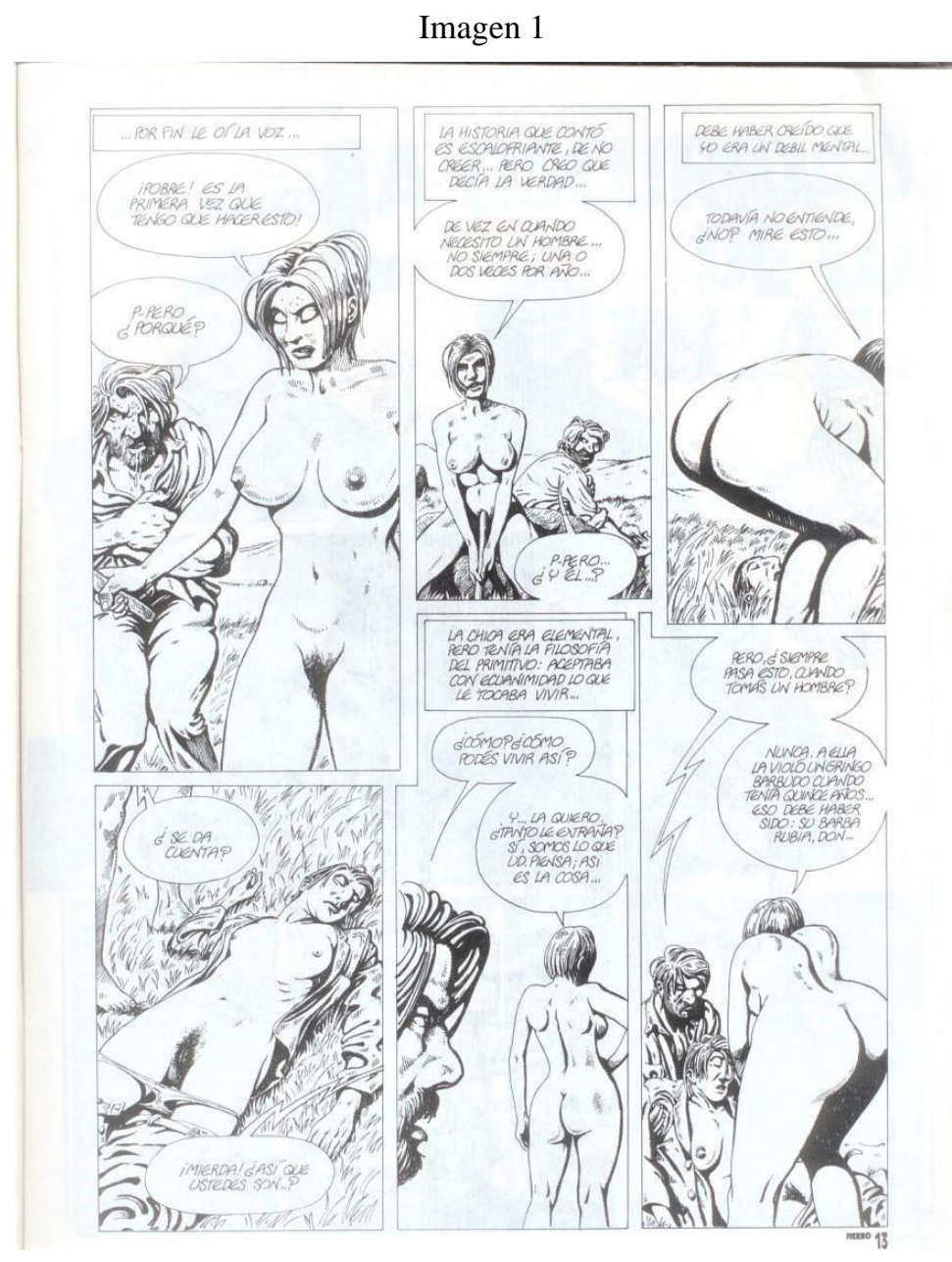

Fonte: Fig. 31.“Señuelo” de Peiró en Fierro 39 noviembre de 1987 p. 13

Pero si asumimos que esa es la sorpresa que remata la historieta, aún nos espera otro giro inesperado que plantea Peiró. El narrador mantiene este diálogo con la salvaje:

Mujer: Ella hizo la casa, de a poco, quería aislarse, no ver a nadie. Yo la conocí en el pueblo. Pescador: Pero ¿vas a vivir siempre así?

Mujer: Y, mientras la cosa ande, sí. Y no voy a dejarla sola.

Pescador: ¿Pero vas a comparar lo que hicimos recién con... con esto?

Mujer: ¡Vos no fuiste nada del otro mundo! ¿Por qué no te mirás un poco por dentro?

(Fierro 39, p. 14)

La resolución de la historia en las dos viñetas que restan para el final depara una nueva sorpresa para la lectora. Tras la furia de la mujer, una viñeta nos reubica en el presente de la narración: se trata de un paisaje urbano y nocturno, sobre el que se destacan los globos de diálogo de los personajes que están compartiendo la anécdota.

Rápidamente podemos distinguir que nuestro narrador se llama Leopoldo y que está contándole su historia a un interlocutor que no llegamos a distinguir pero que es quien pregunta y habilita al narrador a cerrar la historia. La frase "¿Y lo hiciste, Leopoldo?” remite a ese "mirarse por dentro" con el que increpa la mujer al pescador. Antes de mostrar 
nuevamente al protagonista, este responde: "sí, por de pronto dejé la pesca. Me di cuenta de lo que se siente al morder el anzuelo...”.

En la siguiente y última viñeta, vemos a Leopoldo, que se ve muy distinto al pescador que siguió los pasos de la mujer y fue asustado por su amante: ya no luce barba, tiene un corte de pelo a la moda y lleva una remera ajustada que marca sus pectorales. Para dejar claro que su comentario se refiere a que ya no realiza prácticas heterosexuales, lleva un colgante en el que leemos la palabra GAY y unas últimas líneas de diálogo "y lo demás es historia", en las que podemos entrever su salida del armario.

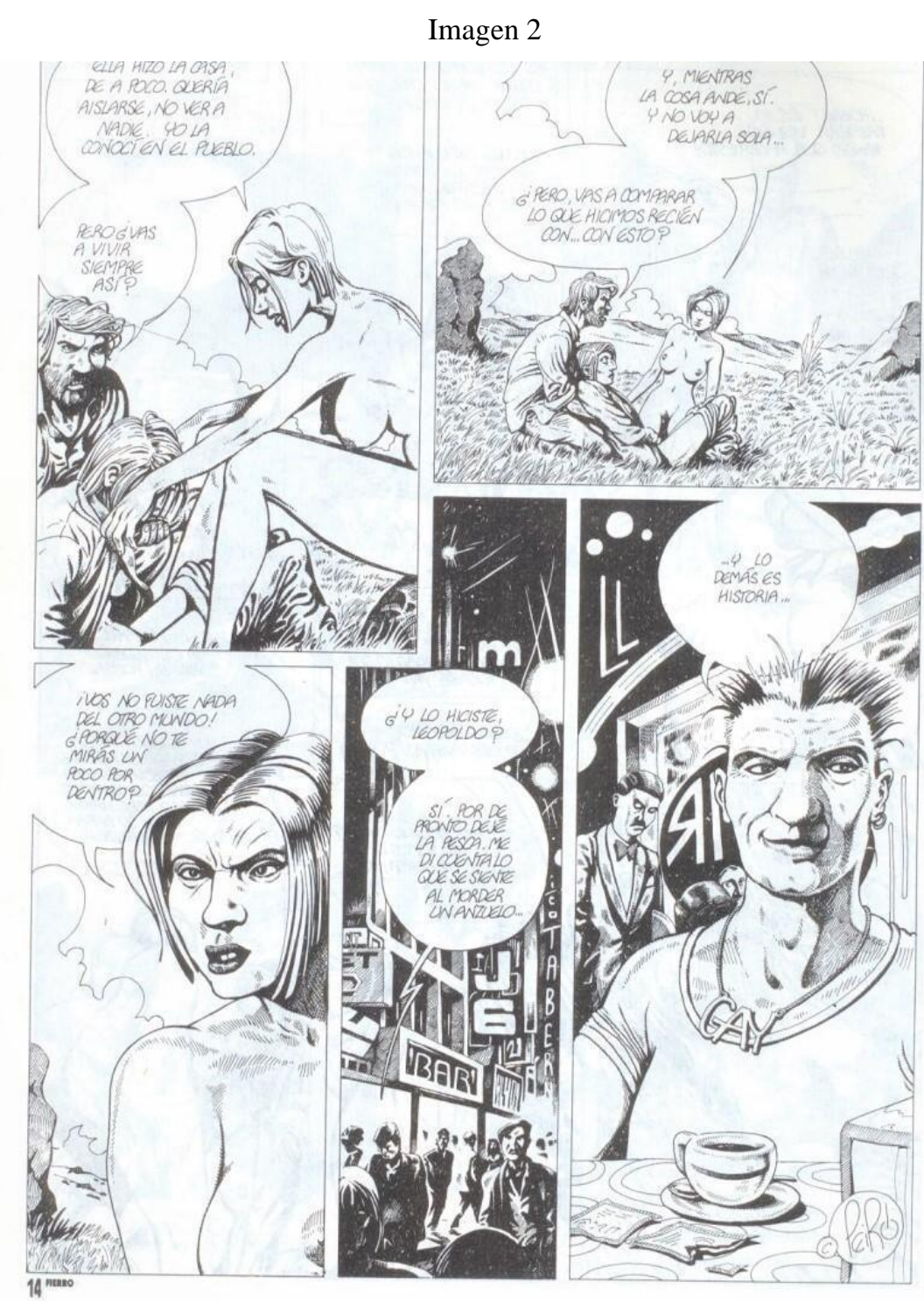

Fonte: Fig. 32 “Señuelo” de Peiró Fierro 39 noviembre 1987 p.14

De esta forma, la historieta presenta tres modelos de masculinidad posibles: una que podríamos señalar como tradicional o hegemónica, otra que se hace visible de forma 
problemática como masculinidad femenina y una tercera que visibiliza la masculinidad gay. La resolución nos plantea algunas cuestiones: por un lado, puede ser leída como una expresión teñida de cierta misoginia. Es decir, un varón heterosexual que se enfrenta a lo monstruoso, que no puede concebir ni se anima a nominar: “¿Así que ustedes son...?”. Los puntos suspensivos se completan con la respuesta de ella: "Sí, somos lo que ud. piensa" pero transformado. Luego de sobrevivir a ese encuentro opta por alejarse, "no volver a morder el anzuelo", de aquello que casi le cuesta la vida. El "Señuelo" del título indicaría que el pescador ha sido seducido y engañado por lo que parecía ser una mujer, pero que resultó ser una trampa.

La historieta plasma sexualidades que parecen abrazar e impugnar definiciones y casillas exactas en las que ubicarse: por un lado, "sí, somos eso" y al mismo tiempo, "de vez en cuando necesito un hombre" conviven en conflicto, muestra como esas categorías limitantes (sobre qué es hombre, que es mujer, qué es lesbiana, que es gay) son desbordadas.

La idea de que Leopoldo se asume como gay después de esta experiencia podría ser leída como una forma de misoginia. Sin embargo, esa interpretación no capta el lugar de mascarada en el que se coloca a la masculinidad. Entre una naturaleza presentada como salvaje y diurna y una ciudad entendida como civilizada y nocturna se tejen las dos polaridades de lo femenino y lo masculino: y como en esas dos espacialidades, hay identidades y sexualidades que no aceptan este ordenamiento sencillo. Porque Peiró no parece naturalizar la heterosexualidad, a la que ubica en el paraje de la pesca, sino que por el contrario puebla ese espacio con aquello que es identificado como "señuelo", las identidades masculinas y femeninas se presentan entonces como construcciones artificiosas, ficciones que regulan los intercambios pero que pueden desbaratarse: podríamos pensar la masculinidad del personaje que irrumpe, como la de una lesbiana masculina o la de un varón trans que es narrado desde una mirada reguladora: es leído como una mujer transgrediendo el orden de género y hay que mostrar la verdad de su sexo. La historieta lo va a mencionar - una vez develada su genitalidad - como "ella" y se dirá que es una mujer vestida de hombre — de hecho, en el momento de mostrar su cuerpo desnudo a quien lee, el personaje usa prendas interiores femeninas - pero, a su vez, el personaje narrador de la situación es mostrado como incapaz de comprender. No entiende que allí donde reclama el coito heterosexual como superior a otras prácticas sexuales se lo reduce a algo "nada del otro mundo" y se lo empuja a revisar su deseo. La masculinidad heterosexual se presenta, entonces, como una mascarada también y hacia el final del relato, la heterosexualidad del protagonista, su impulso "natural", su unión sexual con la salvaje, también se mostrará como una puesta en escena. La 
masculinidad heterosexual que sostiene al cazador, barbudo y recio, se percibe precaria en la idea de que el "mirarse por dentro" lo empuja a replantearse sus prácticas tenidas por naturales y evidentes. La masculinidad o la expresión de cuerpo lesbiano del personaje que irrumpe y que es neutralizado para que podamos ser testigos de su corporalidad nos coloca en el lugar de una voyeuse que certifica que la mascarada ha sido develada, pero aun así deja el inquietante espacio para que lectoras y lectores se pregunten quiénes pueden ser considerados varones si la apariencia y la actitud, la habilidad con las armas y la fuerza, el lenguaje corporal y el reclamo sobre la mujer en disputa pueden ser asumidos por otros cuerpos ¿Sería la genitalidad la única garantía de masculinidad? Si el cuerpo de varón fuga de la heteronorma ¿sigue siendo masculino? ¿Qué otros cuerpos pueden encarnar formas de masculinidad?

Por otro lado, la masculinidad tradicional no parece mostrarse monolítica, sino flexible, maleable por la experiencia y el tiempo. En la escena, la "salida del armario" -expresión que refiere usualmente a la asunción pública de una sexualidad no heteronormativa o disidente- es un proceso en el que interviene un acto reflexivo. En la historieta "ese mirarse por dentro" implica también un reflejarse en la masculinidad disidente que exacerba ciertos rasgos de masculinidad hegemónica: la agresión, la posesión y la competencia con otro varón que disputa a la mujer como trofeo.

Lo interesante, además de lo que nos permita reflexionar sobre la construcción de masculinidades, es que Peiró coloca este breve relato en una revista que en los años ochenta leía el contexto en el que la palabra gay comenzaba a hegemonizar las políticas sexuales del colectivo homosexual. La categoría gay implica otra articulación a la propuesta en los años setenta con la militancia “homosexual”. Emmanuel Theumer (2017:117) señala que

la introducción de la categoría gay cobrará fuerza a lo largo de los años '80 como una identificación sexual y una escenificación político-pública. Sin embargo, este proceso no fue armonioso, no lo es actualmente, ni lo fue en esta temprana politización. A lo largo de los años 80 uno de los conflictos desatados alrededor de la Comunidad Homosexual de Argentina estuvo dado por sus políticas de visibilidad, inicialmente denominada "dignidad" y luego "orgullo", así como por el privilegio otorgado a la categoría gay, en proceso de estetización corporal y de distinción social.

En la historieta, la masculinidad lesbiana o transgeneridad masculina es mostrada y explicada como consecuencia de una mala experiencia con los hombres cis, pero no es mencionada explícitamente: apenas se llega a articular la frase "somos lo que ud. piensa". En cambio, la palabra que brilla en la última viñeta menciona y hace visible gay como categoría e identidad política. Es posible entender también que ese "gay" del collar de alguna manera termine por completar la frase última que se cierra con puntos suspensivos, jugando con la 
naturaleza verbal e icónica de la historieta: "y lo demás es historia... gay", como si lo articulara (aunque sin decirlo en el globo) El collar estaría de esa manera en el punto exacto de un orden binario interrumpiendo, en una zona limítrofe entre palabra y dibujo.

\section{Mi experiencia con Agé y canciones cursis para varones}

Incorporamos ahora a este análisis dos historietas de la segunda etapa en las que se pone en juego la construcción de las masculinidades y que explicitan cuestiones en torno a la orientación sexual o la expresión de género.

"Mi experiencia con Agé" de Juan Saénz Valiente salió publicada en el número 5 de Fierro (marzo de 2007) y luego reeditada en Matufia (Agua Negra, 2017). En su versión original la historieta ocupó tres páginas a dos tonos, blanco y negro con unos tonos violáceos (en la reedición se adaptó a un formato más extenso y en blanco y negro). La propuesta es autobiográfica y la plancha aprieta veinticuatro cuadros por página. Se sostiene en breves diálogos y en la voz en off del narrador que cuenta lo que denomina una "anécdota": su encuentro con un famoso presentador de moda que lo cita en su estudio para ofrecerle trabajo de modelo. 


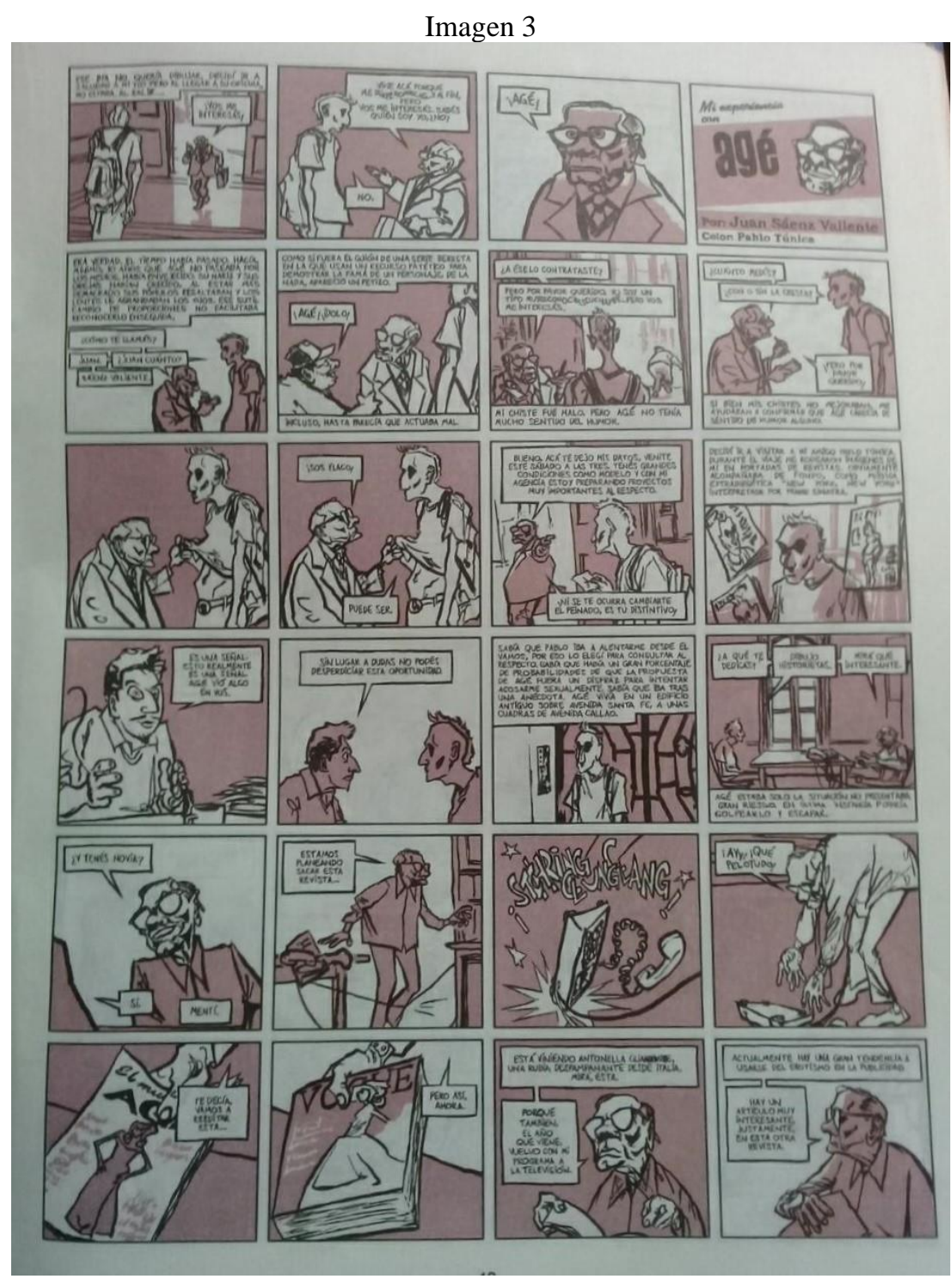

Fonte: “Mi experiencia con Agé” de J. Sáenz Valiente en Fierro 5 (03/2007) p.43

En el relato, el joven dibujante, aunque sospecha que la propuesta entraña intenciones sexuales, decide arriesgarse: "sabía que había un gran porcentaje de probabilidades de que la propuesta de Agé fuera un disfraz para intentar acosarme sexualmente. Sabía que iba tras una anécdota”. En el encuentro en el departamento del presentador, el personaje de Juan le seguirá el juego: se desnuda y viste con la escasa ropa que le ofrece su anfitrión, camina frente al espejo, muestra su cuerpo desgarbado, contesta preguntas íntimas sobre prácticas sexuales y deja que su entrevistador intente producirle una erección. Solo más tarde, en diálogo con otro dibujante — su amigo Pablo Túnica-, comprobará que esa estratagema era una práctica habitual llevada a cabo por Agé para conocer jovencitos. La puesta en página de la historieta pone en circulación un encuentro homoerótico aunque la relación no se concrete: la curiosidad, el miedo y el límite parecen 
entretejerse en la historieta que narra una negociación que finalmente se resuelve en un abrazo de despedida pero que remata, para que no queden dudas del "riesgo" del encuentro, con la afirmación de que otros jovencitos huyeron a la mitad de la charla. La socialización de la experiencia es novedosa, hay pocos relatos en la revista que exploren la sexualidad fuera de la norma heterosexual y la corporalidad observada desde los ojos de otro varón en términos de deseo. La historieta de Saénz Valiente pone en página la posibilidad de recorrer distintas identificaciones entre la heterosexualidad y la homosexualidad, en escenas que bordean el límite entre el deseo y el terror en donde no falta la amenaza a la violencia: "Agé estaba solo. La situación no presentaba gran riesgo. En última instancia podría golpearlo y escapar" narra la voz en off mientras la escena nos muestra la apacible charla de dos varones con una gran diferencia de edad, sentados y separados por un escritorio. Juan se queda, se deja halagar, seducir y embaucar. Cuando sale de su encuentro señala: "Buenos Aires seguía estando ahí afuera, necesité entrar a la galería Bond Street para compensar la situación. Unas semanas después se comentó en los medios que Agé estaba en bancarrota. Pasaron más de 5 años. Aún no me llamó." El relato parece por momentos entender que se trata de una propuesta de encuentro homoerótico que se deja avanzar y por momentos un engaño en el que cae el inocente joven que cree que podría ser una oferta laboral legítima. El relato en su ambigüedad permite señalar que la experiencia narrada presenta contradicciones difíciles de explicar para el propio protagonista que no quiere reconocer el deseo que lo motiva y adjudica solo al hombre que lo intenta seducir.

La última historieta "Canciones cursis para varones" de Ignacio Minaverry fue publicada en Fierro \#40 (febrero de 2010). La página muestra sobre un fondo azul, un texto en rojo con el signo $\delta$ que identifica lo masculino. Una voz en off señala al pie: "muchos artistas, Leonardo Favio por ejemplo, pueden componer excelentes canciones para mujeres, pero la cursilería para varones es otra cosa: requiere de una sinceridad y una capacidad de introspección que los muchachos solemos escamotear hasta que no nos queda otra". Ese narrador, que habla desde un "nosotros, los muchachos", contará la historia de Carlos, un mod de Villa Lugano.

Los mod fueron jóvenes de clase trabajadora que en la Inglaterra de los años cincuenta y sesenta se identificaban con cierto modo de vestir elegante, las motos vespa y la música de The Who. Todo eso aparece sintetizado en las cinco páginas de la historieta que en negro, azul y rojo — colores que remiten a la estética de la banda inglesa The Who- cuentan la historia de un repartidor de pizza que no se avergüenza de su "debilidad por las canciones 
cursis para varones" entre las que el narrador incluye "I'm one", que integra la ópera-rock Quadrophenia (1973) llevada al cine con ese mismo título en (1979).

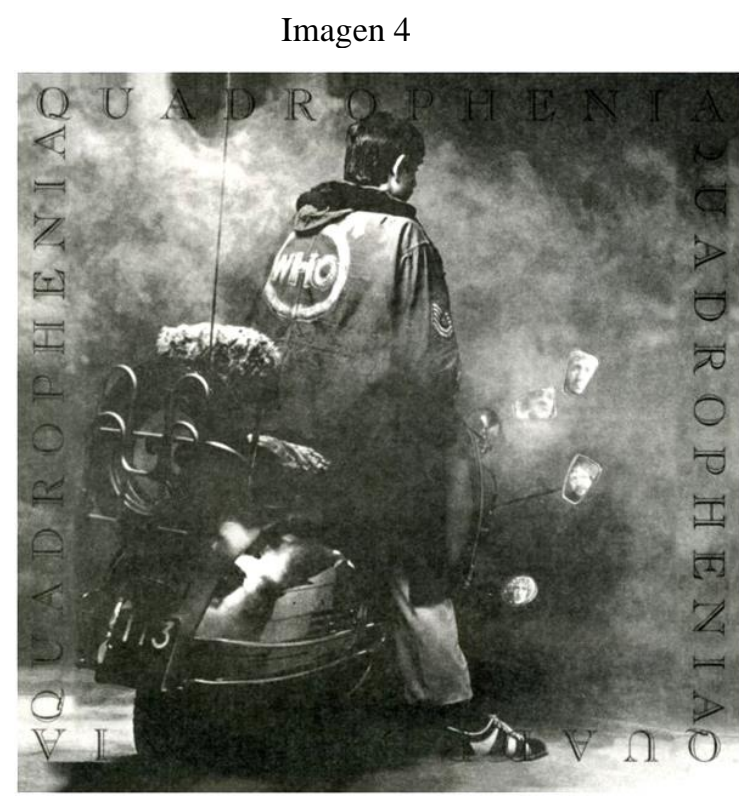

Fonte: Fig. 34. Cubierta de disco Quadrophenia-The Who
Imagen 5

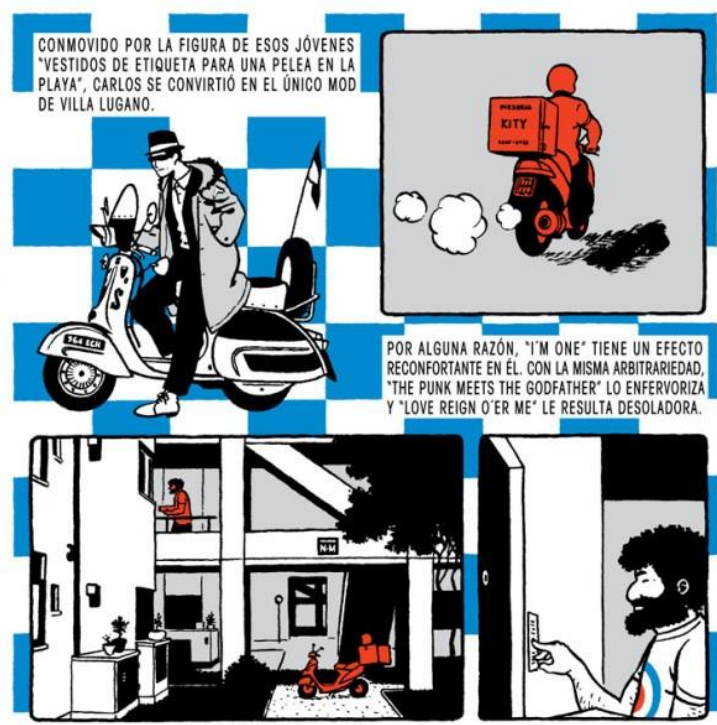

Fonte: Fig. 35. Página 3 de "Canciones cursis..." en Fierro 40 p. 16 (Minaverry)

La letra de la "I'm one" (Soy el único) es una afirmación que realiza un "yo" que podría ser andrógino o desgenerizado. De hecho, el intérprete de se reclama uno en la multitud, tratando de pasar desapercibido y a la vez reafirmando su diferencia pero sin apelar a estereotipos que lo identificarían como varón:

$\begin{array}{cc}\text { But I'm one } & \text { Pero soy únicx } \\ \text { I'm one } & \text { Soy únicx } \\ \text { And I can see } & \text { Y puedo ver } \\ \text { That this is me } & \text { que este soy yo } \\ \text { And I will be } & \text { Y seré yo } \\ \text { You'll all see that } & \text { Ya lo verán } \\ \text { I'm the one } & \text { Que soy el únicx }\end{array}$

El cierre de la historieta muestra a Carlos animándose a invitarle una pizza a "cierta chica que vive cerca de su casa". Allí el personaje se dirige al narrador, que lo amonesta diciéndole "eso no es $\mathrm{mod}$, Carlos", por el gesto romántico de regalarle una rosa a la vecina a la que le lleva una caja de pizza. Ante esto Carlos, mirando al lector, responde: "Bueno, che, no jodas... ¡Si Favio también se la re banca!”.

La sencillez de la historia plagada de citas musicales y referencias culturales recupera una forma de masculinidad sensible y construida de manera mucho más flexible que 
la que se puede observar en otras historietas. Lejos estamos de la épica aventurera y la masculinidad heroica que transitan los héroes tradicionales de la historieta.

A lo largo de este recorrido hemos atravesado distintos momentos y formas en las que la masculinidad fue un elemento relevante para pensar las relaciones entre varones. Kosofsky Sedgwick señala los efectos opresivos sobre las mujeres y los hombres de un sistema cultural en el que el deseo intermasculino se hizo fundamentalmente inteligible mediante su desviación hacia relaciones triangulares que implicaban a una mujer. Con el concepto de homosocialidad, la autora se refiere a las comunidades masculinas que se definen por la exclusión de las mujeres, que están reguladas por el pánico homosexual manifestado en la homofobia pero que presentan intensidades afectivas homoeróticas que son plausibles de convertirse en homosexuales.

Apelamos a los análisis de Eve Kosofsky Sedgwick y su concepto de homosociabilidad para observar desde ese prisma las masculinidades, sus transformaciones en el tiempo, sus silencios, y pudimos observar entonces que esos relatos de la experiencia masculina ponen en circulación una serie de figuraciones que se transforman a lo largo del tiempo.

Hemos recorrido en este capítulo esas intensidades: de la aventura como sinónimo de fraternidad masculina en primer lugar, repensando los modos de habitar masculinidades en cuerpos que escapan a la norma como en "Señuelo" de Peiró, ficción que pone en página formas de competencia masculina y expresan de esta forma un deseo homoerótico, conectadas a las experiencias de narrativas que conectan heterosexualidad y homosexualidad masculina en un continuum antes que en espacios estancos en "Mi experiencia con Agé" de Juan Saenz Valiente para cerrar con una masculinidad heterosexual que se permite la coquetería como rasgo de sensibilidad desgenerizada. Me permito una reflexión final: las historietas que analizamos son textos que construyen un diálogo de homosociabilidad no solo por los personajes masculinos que traban amistades apasionadas en la narración, sino también por la presencia de una mirada masculina — el lector imaginado — a quien se dirige el relato. Leer las historietas desde una "lectora feminista de historietas", una especie de máquina de ficciones desde ciertas coordenadas específicas, nos permite resituar estos relatos en el murmullo social en el que se construyen y reelaboran las identidades sociosexuales. 


\section{Bibliografía}

BERONE, Lucas (2012)“Historieta, discurso político y narración. La revista Fierro, entre dos épocas" en BERONE, L. y REGGIANI, F. (eds.) Creencias bien fundadas. Historieta y política en Argentina, de la transición democrática al kirchnerismo, Universidad Nacional de Córdoba, Escuela de Ciencias de la Información.

BRANZ, Juan Bautista (2017) "Masculinidades y Ciencias Sociales: una relación (todavía) distante" en Descentrada, vol. 1, n 1, marzo 2017, Universidad Nacional de La PlataFacultad de Humanidades y Ciencias de la EducaciónCentro Interdisciplinario de Investigaciones en Género (CInIG) Disponible en línea en https://www.descentrada.fahce.unlp.edu.ar/article/view/DESe006/8001

CABRAL, Mauro (2006) “La paradoja transgénero". En Ciudadanía Sexual.org. Boletín Electrónico del Proyecto Sexualidades, Salud y Derechos Humanos en América Latina, $\mathrm{N}^{\circ} 18$, Año 2. [en línea]. [Consulta: 10 de diciembre 2018]. Disponible en: 〈goo.gl/kPvnjq > .

CLÚA GINÉS, Isabel (2008): “¿Tiene género la cultura? Los estudios culturales y la teoría feminista”. En: CLÚA, Isabel (ed.): Género y cultura popular. Barcelona, Edicions UAB.

CONNELL, RW (1997): “La organización social de la masculinidad”. En Teresa Valdés y José Olavarría (Ed.) Masculinidad/es: poder y crisis. Isis Internacional. Chile.

DI MEGLIO, Gabriel; FRANCO, Marina; SILVA ARAS, Silvina (2005) "La Argentina en cuadritos. Una aproximación a la Argentina reciente desde la revista Fierro" en Entrepasados. Revista de Historia, p. 97 - 115, Buenos Aires.

FOSTER, David William (1997) Sexual Textualities: Essays on Queer/ing Latin American Writing, Texas, University of Texas Press.

(2016) El Eternauta, Daytripper, and Beyond: Graphic Narrative in Argentina and Brazil, Texas: University of Texas.

HALBERSTAM, J. (2008) Masculinidad femenina. Madrid: Egales.

MELO, Adrián (2012) "De la amistad como forma de vida" en Suplemento SOY del 23 de noviembre de 2012, Diario Página 12. Se accede en línea en https://www.pagina12.com.ar/diario/suplementos/soy/1-2719-2012-11-23.html

RUBINO, Atilio (2017) (2017). Sexualidades disidentes en la literatura y el cine de habla alemana (1969-1980). Tesis para la obtención del título Doctor de la Universidad Nacional de La Plata. Facultad de Humanidades y Ciencias de la Educación.

THEUMER. Emmanuel (2017) "Políticas homosexuales en la Argentina reciente (19701990s)" en Interdisciplina Vol 5, No 11, UNAM, México. Disponible en http://revistas.unam.mx/index.php/inter/issue/view/4595/showToc 


\section{Notas}

* Doctora en Ciencias Sociales (2019, UBA), becaria postdoctoral (CONICET, 2020), licenciada y profesora de Ciencias de la Comunicación (2011, 2016 UBA). Desde 2016 integra el Grupo de Trabajo "Estudios de Género y Feminismos en América Latina" (GEFAL) del Instituto de Estudios de América Latina y el Caribe (IEALCUBA) y desde 2019 el GT "Red de género, feminismos y memorias de América Latina y el Caribe" (CLACSO). Se desempeña como docente en la Universidad Metropolitana del Estudio y el Trabajo (UMET).

https://orcid.org/0000-0002-4071-0555.

${ }^{\text {i }}$ Para un análisis de las relaciones de homosociabilidad en la literatura infantil y juvenil (España) puede consultarse el texto de Fátima Arranz (2015). En el ámbito local Romina Smiraglia (2015), a partir de este concepto de homosociabilidad entre varones herosexuales en el lenguaje cinematográfico, en "Nuevas formas de la homosociabilidad en el cine argentino contemporáneo: el bromance como estrategia en Excursiones (de Ezequiel Acuña)" disponible en línea.

ii Diez de sus unitarios de esa primera época de Fierro fueron compilados bajo el título de Tinta Mortal en la Colección Continuará de la que fue responsable la dirección de Fierro en su segunda época (Ed. La Página 2014). Una compilación posterior, Cordoba Blues, del sello Hotel de las Ideas (2018), reunió veintidós unitarios publicados en Fierro, Hum®, SuperHum ${ }^{\circledR}$ y Raf, además de una historieta inédita. 